\title{
Selected molecular and physiological aspects of mammalian ovarian granulosa cells in primary culture1)
}

\author{
WIES ŁAWA KRANC*, ADRIAN CHACHUŁA**, ARTUR BRYJA*, SYLWIA CIESIÓŁKA**, \\ JOANNA BUDNA**, KATARZYNA WOJTANOWICZ-MARKIEWICZ ${ }^{* *, * * *}$, EWA SUMELKA**, \\ SYLWIA BORYS*, PAWE ${ }^{*}$ ANTOSIK***, DOROTA BUKOWSKA**, MAŁGORZATA BRUSKA*, \\ MICHAŁ NOWICKI**, BARTOSZ KEMPISTY*,**
}

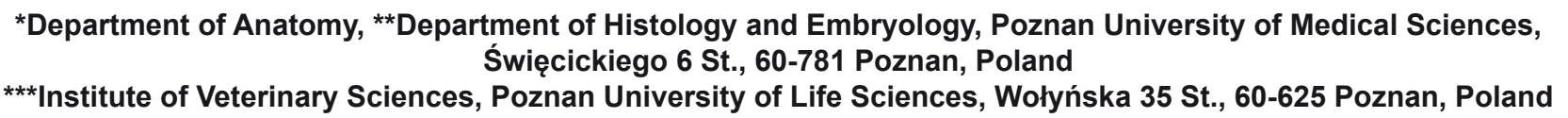

Kranc W., Chachuła A., Bryja A., Ciesiółka S., Budna J., Wojtanowicz-Markiewicz K., Sumelka E., Borys S., Antosik P., Bukowska D., Bruska M., Nowicki M., Kempisty B.

Selected molecular and physiological aspects of mammalian ovarian granulosa cells in primary culture

Summary

The ovary is a complex endocrine gland that is responsible for sex steroid production in mammals. The basic functional unit of the ovary is the follicle, which contains the oocyte $(\mathrm{OC})$, and surrounding cells, including granulosa cells (GCs) and theca cells, which support $\mathrm{OC}$ development. The process of formation and development of a follicle is known as folliculogenesis, during which the proliferation and differentiation of the GCs are required for proper formation of the follicle. In this review article, we present an overview of the molecular aspects of oogenesis and folliculogenesis, with subsequent description of mammalian ovulation. Moreover, we describe how growth, proliferation, and differentiation of GCs is regulated on a molecular level across mammalian species. Based on recent scientific reports, we depict possible biomedical applications and propose directions for future research using mammalian GCs in primary culture.

Keywords: ovarian follicle, granulosa cells, primary culture

\section{Oogenesis and folliculogenesis - molecular overview}

Oogenesis is the process by which oocytes are formed. The female germ cell (oocyte) develops in the ovarian follicle (17). Oogenesis is long-term process that starts during fetal life and ends to form the oocyte in postnatal life (35). Among most of mammalian species oogenesis process consists of several stages: (I) primordial germ cells, (II) formation of oogonia from primordial germ cells, (III) formation of stage I oocyte, (IV) stage II oocyte, and (V) formation of an adult follicle (Graafian follicle) with fully mature oocytes. However this classification is not applicable to all mammals, i.e.: oocytes in bitches mature after ovulation in the oviduct. The process parallel to oogenesis is folliculogenesis, which during postnatal life leads to maturation of fully grown follicles (Graafian follicles) and takes place following

1) Publication of this article was made possible by grant number 2014/13/D/ NZ9/04798 "SONATA" from the Polish National Centre of Science. ovulation (31). Primordial follicles are formed by germ cell cysts. Primordial follicles contain a small oocyte surrounded by a population of granulosa cells. At this stage, granulosa cells are characterized by a flat shape. The next stage begins primordial follicle activation. During this process, oocytes grow and the shape of the granulosa cells changes from flat to cuboidal in structure (44).

Folliculogenesis and oogenesis are regulated mainly by gonadotropins. Gonadotropins, including follicular stimulating hormone (FSH) and luteinizing hormone (LH), play a crucial role in the growth and maturation of follicles as well as in development of the oocyte. The FSH receptors (FSHRs) are expressed in granulosa cells (GCs) during the early-antral stage. In this phase of folliculogenesis, FSH induces proliferation of GCs, prevents follicular atresia, and stimulates expression of LH receptors (LHR). Subsequently increase of estrogen production leads to an LH surge, which initiates 
a series of events i.e.: resumption of meiosis, expansion of cumulus cells (CCs) and finally leads to ovulation.

During oogenesis the oocyte undergoes dynamic changes of genes expression, which is regulated by transcription factors active in the germ line and somatic cells that surround the oocyte. Transcriptional regulators, such as Foxo3, Fox12, Figla, Lhx8, Nobox, Sohlh1, and Sohlh2, play an important role in the formation of antral follicles during folliculogenesis. It was found that mutations in any of these genes may lead to ovarian insufficiency and infertility in mammals. Studies of these transcriptional factors present opportunities to better understand the mechanisms of activation of ovarian follicle growth and its regulation (20).

Ren et al. (44) investigated the role of oocyte-specific pathways during primordial follicle activation. Their studies suggest that Lhx8 plays a crucial role in the differentiation of primary follicles and that a deficiency in $L H X 8(-/-)$ causes infertility. $L H X 8$ is expressed in oocyte and germ cells in mammals. The encoded protein belongs to the family of LIM-homeobox transcription factors. An earlier study by Choi et al. (8) showed that mice with $L H X 8$ deficiency were characterized by a lack of transition of primordial follicles into the growing follicles.

Monti et al. (40) studied expression of oogenesis-related specific genes, such as Nobox, Oct4, Bmp15, Gdf9, Oogenesis1, and oogenesis2, during natural development and under gonadotropin induction in mice. Oocytes were collected from five types of murine ovarian follicles: primordial, primary, secondary, preantral, and antral follicles. Semi-quantitative, single-cell sensitive RT-PCR techniques and immunocytochemical study were used as detection methods. Experimental results demonstrated that these genes are differentially expressed in natural and gonadotropin-induced mice. For example, Gdf9 and Bmp 15 are expressed during all phases of oocyte maturation. In $G d f 9-/$ - mice, oocytes cannot mature beyond the primary follicle stage (40) because granulosa cells do not proliferate into cuboidal cells (11).

The transcription factor Nobox plays an important role during oogenesis and formation of fully mature stage II oocytes. The absence of its protein product leads to a lack of transition from primordial into growing follicles and results in down-regulation of the expression of a number of genes encoding proteins for transcription factors that regulate the ability of oocytes to reach full developmental capacity, such as H1oo, Gdf9, Bmp15, Dnmt1o, Zar1, FGF8, Rfp14, Mos, and Oct4 (41, 42). Belli et al. (3) studied the pattern of expression of the Nobox gene and its protein during folliculogenesis. They used oocytes classified on the basis of their size (10-30, $31-40,41-50,51-60,61-70$, or 71-80 $\mu \mathrm{m}$ ) and chromatin organization [non-surrounded nucleolus (NSN) or surrounded nucleolus (SN)]. Differences in Nobox gene expression were assessed in oocytes 41-50 $\mu \mathrm{m}$ $(\mathrm{NSN}>\mathrm{SN})$ and $71-80 \mu \mathrm{m}(\mathrm{NSN}>\mathrm{SN})$ as well as in developmentally incompetent metaphase II-derived
NSN (MII(NSN)) or competent metaphase II-derived $\mathrm{SN}(\mathrm{MII}(\mathrm{SN}))$ oocytes $(\mathrm{MII}(\mathrm{NSN})>\mathrm{MII}(\mathrm{SN}))$. The Nobox protein was expressed throughout oocyte growth in the nucleus of ovarian NSN and in MII(NSN) oocytes, whereas the Nobox protein was not expressed in SN oocytes of 61-70 $\mu \mathrm{m}$. These findings indicate that expression of Nobox gene is increasing during growth of oocytes and decreases while oocytes are full-grown. Moreover, differences in expression of Nobox indicate that it is a determinant of oocyte quality.

Zuccootti et al. (53) emphasize that the role of the Oct4 gene in folliculogenesis and oogenesis is as of yet unknown, but suggest that this gene may play a potential role in the acquisition of oocyte developmental competence in the mouse. Their studies show the presence of an Oct4 transcriptional network in MII oocytes and 2-cell embryos. The Oct4-gene regulatory network provides a connection between the oocyte, early preimplantation embryos, and embryonic stem cells. Zuccotti et al. suggested that future experiments should be performed to elucidate the regulation of transcription and translation of Oct4 and related genes during early oocyte growth and preimplantation development up to the point of blastocyst implanting.

\section{Physiological and molecular aspects of ovulation - "in the shadow" of GC differentiation capacity}

The antral follicle is composed of an oocyte, antrum and multilayer of granulosa cells (GCs) (10). It has been well described that proper zygote formation and development of embryos require bidirectional communication between GCs and oocyte. This communication is allowed by connexins which form gap junction connections (GJCs), a kind of "corridor" between somatic and germ cell, which are used to transfer small substances and factors regulating folliculo- and oogenesis (18).

During folliculogenesis the GCs undergo substantial changes and modification of shape from flattened to cuboidal, which is accompanied by differential expression of FSHR. In a pre-ovulatory follicle, four layers of GCs are observed. The innermost layer of GCs surrounding an oocyte is the tightly attached corona radiata, followed by the cumulus oophorus on its periantral layer, and the membrana granulosa, which is the most externally distributed. These four layers have another function in the Graafian follicle; for example, cells in the central domain proliferate for a longer time than cells in the membrane domain. This phenomenon suggests that the GCs have the opportunity to specialize and can perform various functions. The process of oocyte maturation involves resumption of meiosis that have been arrested in prophase I; what is more, nuclear maturation is tightly connected with the disappearance of the nuclear membrane, haploidization of genetic material and with ejection of the first polar body. This cascade of events is caused by an LH surge that results in a reduced amount of cAMP level, which leads to decreased activity of cAMP-dependent kinases and maturation promoting factor (MPF). 
Ovulation is the process during which the oocyte is released. Ovulation is characterized by rupture of the ovarian surface epithelium and the release of an oocyte (18). Ovulation is subject to strict control of extracellular matrix modifications. In a large number of mammals, degradation of the perifollicular matrix before ovulation is supported by mural granulosa cells. The follicular apex forms a thinner layer while, at the same time, cumulus cells around the oocyte synthesize and deposit an additional extracellular matrix. This process is called cumulus expansion or mucification. During ovulation, the follicle apex breaks allowing passage of the cumulus cells through the opening followed by the passage of the oocyte. This transition is permitted by deformation of the cumulus matrix. The oocyte is very rapidly extruded from the mature follicle. During extrusion the oocyte and cumulus cells are very strongly associated within the matrix and they are not dispersed (15).

Chen et al. (7) inhibited synthesis of the mucoid and elastic matrix by cumulus cells in mice. They observed that the rupture of the follicle leads to a small number of oocytes that were released from the follicle. It was also found that cumulus cells stayed in the ovarian bursa and were not transferred into the oviduct. These cases support findings that expanded cumulus cells may play a crucial role in the transfer of oocytes from the ovary by the ciliated epithelium of the fimbria (36). Rankin et al. and Liu et al. investigated ZP3 null (-/-) mutant mice and observed that this mutation caused lack of zona pellucida, which was separated from the expanding cumuli in the Graafian follicle. In knock-out mice cumulus cells were successfully recovered from the oviduct soon after ovulation, whereas oocytes were not observed in the oviduct. They suggested that the oocytes may be trapped in ruptured follicles. Moreover, other zona-free oocytes may dissociate from the cumulus during ovulation and might undergo degeneration after contact with the female reproductive tract epithelium $(33,43)$.

\section{Regulation of growth, proliferation, and differentiation of follicular granulosa cells}

Growth, proliferation, and differentiation of cells are key biological processes, which are usually regulated by extracellular factors that interfere with regulation of the cell cycle and change gene expression. This mechanism also occurs in the mammalian ovary during folliculogenesis. The follicle is the basic functional unit of the mammalian ovary. Each follicle is composed of a single oocyte encircled by inner layers of granulosa cells (GCs) and outer layers containing theca cells (TCs). In the mammalian ovary, development of individual follicles is controlled by different hormones resulting in continuous, dynamic changes in proliferation and gene expression in granulosa cells. During folliculogenesis, GCs start to form gap junctions (GJs) between themselves and the oocyte resulting in bidirectional stimulation and communication $(24,41)$. As an effect of this relationship, GCs stimulate OC maturation while the $\mathrm{OC}$ increases $\mathrm{GC}$ proliferation rate and induces GC differentiation (5). Intensive proliferation and complete differentiation of GCs is required for proper follicular growth.

Mammalian ovaries and testes develop from genital ridges that are composed of precursors of the main types of cells located in completely developed ovaries and testes, i.e. germ cells, supporting cells, and steroidogenic cells. Supporting cell precursors (SCP) differentiate first (34) and without the influence of the $S R Y$ gene from pregranulosa cells (pGC). It has been reported in sheep that pGCs and oocytes create cell complexes, which form ovigerous cords that finally develop into primordial follicles (46). The primordial follicle contains an undifferentiated OC that is surrounded by a single layer of squamous GCs arrested in $\mathrm{G}_{0}$. Primordial follicles enter into the slow-growth phase in which GCs start cycling, but the proliferation rate is low. Over time GCs change their morphology from squamous to cuboidal. After this change, GCs form the primary follicle and express follistatin. Throughout this stage, GCs develop gap junctions between themselves and the OC and also between adjacent GCs. Gap junctions between GCs and the OC are built mainly of Connexin 37 (Cx37) and gap junctions between GCs are formed mainly from Connexin $43(\mathrm{Cx} 43)(25,26)$. Connections between GCs and the OC allow for direct transfer of ions, metabolites, amino acids, and other interceullular signaling molecules (5). During the primary follicle stage, the OC secretes growth/differentiation factor-9 (GDF-9) and bone morphogenic protein-15 (BMP-15), which are crucial for GC proliferation and development (51). GDF-9 expression is necessary for GCs to secrete KIT ligand (KITL) at a normal level, which is necessary for normal oocyte development. If there is no expression of GDF-9, KITL expression is elevated and ultimately leads to oocyte death (12). The majority of estradiol in follicles is secreted by GCs, while GCs also serve as an estradiol target and have been shown to express estrogen receptors (ER $\alpha$ and $E R \beta)$ in various mammalian species, including cow, sheep, and pig $(4,16,21)$. Autocrine estradiol signaling increases expression of gonadotropins receptors as well as inhibition of GC apoptosis (45). Apoptosis repression is based on the ability of estradiol to inhibit the transcription of proapoptotic genes (i.e. p53 and $\mathrm{Bax}$ ) (48). During the primary follicle stage, GCs express both insulin growth factor-I (IGF-I) and its receptor (IGF-IR) across mammalian species $(2,50,52)$ and expression of IGF-I reaches its maximum level in the late preantral and early antral stages. IGF-I also increases expression of $\mathrm{LH}$ receptors and responsiveness to $\mathrm{FSH}$, which is reported to enhance aromatase production in the in vitro culture of mouse, sheep, and pig GCs $(1,37,39)$. IGF-I has also been reported to increase the expression of estradiol in GCs (14). Conversely, in 2000 Khalid et al. discovered that estradiol or FSH stimulate synthesis of IGF-I (27). These three molecules are crucial for proper $\mathrm{GC}$ and follicular growth, proliferation and develop- 
ment, and any anomalies in their expression could be lethal for the follicle and its residual cells, including GCs and the OC. It has recently been reported that nerve growth factor (NGF) can also induce expression of FSH and LH receptors, as well as influence secretion of progesterone and estrogen in GCs $(6,22,23)$. Throughout the stage of forming the secondary follicle (antral follicle), GCs increase their proliferation rate and finally form a two to three layer thick surrounding for an OC. Transition between the preantral and antral follicle stage is an important step in GC differentiation. Formation of a fluid-filled antrum and FSH secretion from the pituitary gland induces differentiation of GCs into two populations: mural GCs adjacent to the follicle wall and cumulus GCs that tightly surround the OC (32). These two populations of GCs have different functions. Mural GCs are responsible for endocrine functions, including steroidogenesis, while cumulus GCs, through bidirectional communication with the $\mathrm{OC}$, induce growth and developmental competence of the OC. Together, coordination between the OC and mural and cumulus GCs and their secreted molecules promote correct follicle growth, development, and endocrine functioning. Mural GCs express increasing amounts of estrogen over time that finally lead to initiation of the LH surge from the pituitary, maturation of oocyte, cumulus oophorus expansion, and ultimately ovulation $(13,19)$. A characteristic function of cumulus GCs is their ability to expand inside the follicle after the LH surge. Cumulus expansion is tightly connected with production of a mucified matrix that is crucial for ovulation (7). The OC is responsible for induction of cumulus expansion after the LH surge by secretion of cumulus expansion enabling factors (CEEFs), which likely include GDF-9 and/or BMP-15 (47). Expansion of cumulus GCs is tightly connected with formation of the cumulus-oocyte complex (COC). It has been reported that the $\mathrm{OC}$ is a main regulator of cumulus GC functions through the SMAD2/3 signaling pathway (9), while mural GCs are under the influence of FSH. These two signaling pathways specify properties and functions of cumulus and mural GCs inside the follicle to ensure optimal conditions for proper developmental and endocrine functions.

\section{Possible applications of mammalian granulosa cells in primary culture}

Over the years, scientists have established reliable and effective methods for isolating and culturing GCs for research applications. Based on study of GCs in primary culture, scientists have described not only the ultrastructure of GCs, but also many signaling pathways that regulate GC development, growth, and differentiation. As far as we know, GCs play a very important role in folliculogenesis and thus in ovulation. Interaction between GCs and other cells in developing mammalian follicles has been well-described in the literature (6), but recent discoveries allow us to expand our knowledge about GCs and can lead to new applications of
GCs in primary culture. It has been shown in several publications that some GCs in the growing follicle are not fully differentiated and exhibit stem cell properties across mammals, i.e.: ovine, porcine and human GCs $(28,29,38,49)$. Besides stem cell properties, GCs also present high telomerase activity and are capable of differentiation into cell types that are not present within ovaries. GCs can be easily obtained from follicular fluid discarded during in vitro fertilization procedures, which may serve as a great source of cells for further use in regenerative medicine. Premature ovarian failure or chemotherapy could terminate the production of sex hormones and cause loss of ovarian functions. GCs with stem-cell like abilities may be particularly helpful in the regeneration of ovarian functions. As GCs are also responsible for secretion of sex hormones, they may also be useful in the regeneration of ovarian endocrine functions. The most promising findings from human GC culture in support of their use in regeneration of endocrine functions were obtained in 2010. The three dimensional (3D) culture of GCs, which ensured longterm maintenance, growth, and also allowed enrichment with luteinizing GCs, was established by Kossowska et al. (30). Moreover, this 3D culture system allowed GCs to grow into spherical structures that exhibit steroidogenic capability.

Further research on GCs on the molecular, cellular, and tissue level will help scientists to understand, describe, and perhaps design new therapies for granulosa cell tumors and their recurrence. Profound knowledge about GCs could also be helpful in better understanding some aspects of infertility. More detailed information about proliferation and long-term culture of GCs could provide an opportunity to develop new cellular therapies and to create artificial tissue, which may be able to produce sex steroids and could be used to re-establish lost ovarian endocrine functions.

\section{References}

1. Adashi E. Y., Resnick C. E., D’Ercole A. J., Svoboda M. E., Van Wyk J. J.: Insulin-like growth factors as intraovarian regulators of granulosa cell growth and function. Endocr. Rev. 1985, 6, 400-420.

2. Armstrong D. G., Gutierrez C. G., Baxter G., Glazyrin A. L., Mann G. E., Woad $K . J ., \operatorname{Hogg} C$. O., Webb R.: Expression of mRNA encoding IGF-I, IGF-II and type 1 IGF receptor in bovine ovarian follicles. J. Endocrinol. 2000, 165, 101-113.

3. Belli M., Cimadomo D., Merico V., Redi C. A., Garagna S., Zuccotti M.: The NOBOX protein becomes undetectable in developmentally competent antral and ovulated oocytes. Int. J. Dev. Biol. 2013, 57, 35-39.

4. Berisha B., Pfaffl M. W., Schams D.: Expression of estrogen and progesterone receptors in the bovine ovary during estrous cycle and pregnancy. Endocrine 2002, 17, 207-214

5. Buccione R., Schroeder A. C., Eppig J. J.: Interactions between somatic cells and germ cells throughout mammalian oogenesis. Biol. Reprod. 1990, 43, 543-547.

6. Chaves R. N., Alves A. M., Lima L. F., Matos H. M., Rodrigues A. P., Figueiredo $J$. R.: Role of nerve growth factor (NGF) and its receptors in folliculogenesis. Zygote. 2013, 21, 187-197.

7. Chen L., Russell P. T., Larsen W. J.: Functional significance of cumulus expansion in the mouse: roles for the preovulatory synthesis of hyaluronic acid within the cumulus mass. Mol. Reprod. Dev. 1993, 34, 87-93.

8. Choi Y., Ballow D. J., Xin Y., Rajkovic A.: Lim homeobox gene, lhx8, is essential for mouse oocyte differentiation and survival. Biol. Reprod. 2008, $79,442-449$ 
9.Diaz F. J., Wigglesworth K., Eppig J. J.: Oocytes determine cumulus cell lineage in mouse ovarian follicles. J. Cell Sci. 2007, 120, 1330-1340.

10.Dzafic E., Stimpfel M., Virant-Klun I.: Plasticity of granulosa cells: on the crossroad of stemness and transdifferentiation potential. J. Assist. Reprod. Genet. 2013, 30, 1255-1261

11. Elvin J. A., Clark A. T., Wang P., Wolfman N. M., Matzuk M. M.: Paracrine actions of growth differentiation factor-9 in the mammalian ovary. Mol. Endocrinol. 1999, 13, 1035-1048.

12. Elvin J. A., Yan C., Matzuk M. M.: Oocyte-expressed TGF-beta superfamily members in female fertility. Mol. Cell Endocrinol. 2000, 159, 1-5.

13. Eppig J. J.: Oocyte control of ovarian follicular development and function in mammals. Reproduction 2001, 122, 829-838.

14. Glister C., Tannetta D. S., Groome N. P., Knight P. G.: Interactions between follicle-stimulating hormone and growth factors in modulating secretion of steroids and inhibin-related peptides by nonluteinized bovine granulosa cells Biol. Reprod. 2001, 65, 1020-1028.

15. Gui L. M., Joyce I. M.: RNA interference evidence that growth differentiation factor- 9 mediates oocyte regulation of cumulus expansion in mice. Biol. Reprod. 2005, 72, 195-199.

16. Hanioka T., Shizukuishi S., Tsunemitsu A.: Changes in hemoglobin concentration and oxygen saturation in human gingiva with decreasing inflammation. J. Periodontol. 1991, 62, 366-369.

17. Heeren A. M., van Iperen L., Klootwijk D. B., de Melo Bernardo A., Roost M. S., Gomes Fernandes M. M., Louwe L. A., Hilders C. G., Helmerhorst F. M., van der Westerlaken L. A., Chuva de Sousa Lopes S. M.: Development of the follicular basement membrane during human gametogenesis and early folliculogenesis. BMC Dev. Biol. 2015, 15, 4 .

18. Hurk R. V. D., Zhao J.: Formation of mammalian oocytes and their growth, differentiation and maturation within ovarian follicles. Theriogenology 2005 , $63,1717-1751$

19. Hussein T. S., Thompson J. G., Gilchrist R. B.: Oocyte-secreted factors enhance oocyte developmental competence. Dev. Biol. 2006, 296, 514-521.

20. Jagarlamudi K., Rajkovic A.: Oogenesis: transcriptional regulators and mouse models. Mol. Cell Endocrinol. 2012, 356, 31-39.

21. Juengel J. L., Heath D. A., Quirke L. D., McNatty K. P.: Oestrogen receptor alpha and beta, androgen receptor and progesterone receptor mRNA and protein localisation within the developing ovary and in small growing follicles of sheep. Reproduction 2006, 131, 81-92.

22. Kempisty B., Ziolkowska A., Ciesiolka S., Piotrowska H., AntosikP., Bukowska D., Brussow K. P., Nowicki M., Zabel M.: Expression and cellular distribution of estrogen and progesterone receptors and the real-time proliferation of porcine cumulus cells. Zygote. 2015, 23, 836-845.

23. Kempisty B., Ziolkowska A., Ciesiolka S., Piotrowska H., AntosikP., Bukowska D., Nowicki M., Brussow K. P., Zabel M.: Association between the expression of LHR, FSHR and CYP19 genes, cellular distribution of encoded proteins and proliferation of porcine granulosa cells in real-time. J. Biol. Regul. Homeost. Agents 2014, 28, 419-431.

24. Kempisty B., Ziolkowska A., Ciesiolka S., Piotrowska H., AntosikP., Bukowska D., Nowicki M., Brussow K. P., Zabel M.: Study on connexin gene and protein expression and cellular distribution in relation to real-time proliferation of porcine granulosa cells. J. Biol. Regul. Homeost. Agents 2014, 28, 625-635.

25. Kempisty B., Ziolkowska A., Piotrowska H., Ciesiolka S., AntosikP., Bukowska D., Zawierucha P., Wozna M., Jaskowski J. M., Brussow K. P., Nowicki M. Zabel M.: Short-term cultivation of porcine cumulus cells influences the cyclin-dependent kinase $4(\mathrm{Cdk} 4)$ and connexin $43(\mathrm{Cx} 43)$ protein expression - a real-time cell proliferation approach. J. Reprod. Dev. 2013, 59, 339-345.

26. Kempisty B., Ziolkowska A., Piotrowska H., Zawierucha P., Antosik P., Bukowska D., Ciesiolka S., Jaskowski J. M., Brussow K. P., Nowicki M., Zabel M.: Real-time proliferation of porcine cumulus cells is related to the protein levels and cellular distribution of Cdk4 and Cx43. Theriogenology. 2013, 80, 411-420

27. Khalid M., Haresign W., Luck M. R.: Secretion of IGF-1 by ovine granulosa cells: effects of growth hormone and follicle stimulating hormone. Anim. Reprod. Sci. 2000, 58, 261-272.

28. Kossowska-Tomaszczuk K., De Geyter C.: Cells with stem cell characteristic in somatic compartments of the ovary. Biomed. Res. Int. 2013, 2013, 310859

29. Kossowska-TomaszczukK., De Geyter C., De Geyter M., Martin I., Holzgreve W., Scherberich A., Zhang H.: The multipotency of luteinizing granulosa cells collected from mature ovarian follicles. Stem Cells. 2009, 27, 210-219.

30. Kossowska-Tomaszczuk K., Pelczar P., Guven S., Kowalski J., Volpi E., De Geyter C., Scherberich A.: A novel three-dimensional culture system allows prolonged culture of functional human granulosa cells and mimics the ovarian environment. Tissue Eng Part A. 2010, 16, 2063-2073.

31. Krysko D. V., Diez-Fraile A., Criel G., Svistunov A. A., Vandenabeele P., $D$ 'Herde $K$.: Life and death of female gametes during oogenesis and folliculogenesis. Apoptosis 2008, 13, 1065-1087.
32. Kumar T. R., Wang Y., Lu N., Matzuk M. M.: Follicle stimulating hormone is required for ovarian follicle maturation but not male fertility. Nat. Genet. 1997, 15, 201-204

33. Liu C., Litscher E. S., Mortillo S., Sakai Y., Kinloch R. A., Stewart C. L., Wassarman P. M.: Targeted disruption of the $\mathrm{mZP} 3$ gene results in production of eggs lacking a zona pellucida and infertility in female mice. Proc. Natl. Acad. Sci. USA 1996, 93, 5431-5436.

34. Lovell-Badge R.: The role of Sry in mammalian sex determination. Ciba Found Symp. 1992, 165, 162-179; discussion 179-182.

35. MacLennan M., Crichton J. H., Playfoot C. J., Adams I. R.: Oocyte development, meiosis and aneuploidy. Semin Cell Dev Biol. 2015, 45, 68-76.

36. Mahi-Brown C. A., Yanagimachi R.: Parameters influencing ovum pickup by oviductal fimbria in the golden hamster. Gamete Res. 1983, 8, 1-10.

37. Maruo T., Hayashi M., Matsuo H., Ueda Y., Morikawa H., Mochizuki M.: Comparison of the facilitative roles of insulin and insulin-like growth factor I in the functional differentiation of granulosa cells: in vitro studies with the porcine model. Acta Endocrinol. (Copenh) 1988, 117, 230-240.

38. Mattioli M., Gloria A., Turriani M., Berardinelli P., Russo V., Nardinocchi D. Curini V., Baratta M., Martignani E., Barboni B.: Osteo-regenerative potential of ovarian granulosa cells: an in vitro and in vivo study. Theriogenology 2012 $77,1425-1437$

39. Monniaux D., Pisselet C.: Control of proliferation and differentiation of ovine granulosa cells by insulin-like growth factor-I and follicle-stimulating hormone in vitro. Biol. Reprod. 1992, 46, 109-119.

40. Monti M., Redi C.: Oogenesis specific genes (Nobox, Oct4, Bmp15, Gdf9, Oogenesin1 and Oogenesin2) are differentially expressed during natural and gonadotropin-induced mouse follicular development. Mol. Reprod. Dev. 2009, 76, 994-1003.

41. Mora J. M., Fenwick M. A., Castle L., Baithun M., Ryder T. A., Mobberley M. Carzaniga R., Franks $S$., Hardy K.: Characterization and significance of adhesion and junction-related proteins in mouse ovarian follicles. Biol. Reprod. 2012, 86, 153, 151-114.

42. Rajkovic A., Pangas S. A., Ballow D., Suzumori N., Matzuk M. M.: NOBOX deficiency disrupts early folliculogenesis and oocyte-specific gene expression. Science 2004, 305, 1157-1159.

43. Rankin T., Familari M., Lee E., Ginsberg A., Dwyer N., Blanchette-Mackie J., Drago J., Westphal H., Dean J.: Mice homozygous for an insertional mutation in the Zp3 gene lack a zona pellucida and are infertile. Development. 1996, 122, 2903-2910.

44.Ren Y., Suzuki H., Jagarlamudi K., Golnoski K., McGuire M., Lopes R., Pachnis V., Rajkovic A.: Lhx8 regulates primordial follicle activation and postnatal folliculogenesis. BMC Biol. 2015, 13, 39

45. Robker R. L., Richards J. S.: Hormone-induced proliferation and differentiation of granulosa cells: a coordinated balance of the cell cycle regulators cyclin D2 and p27Kip1. Mol. Endocrinol. 1998, 12, 924-940.

46. Sawyer H. R., Smith P., Heath D. A., Juengel J. L., Wakefield S. J., McNatty $K$. $P$.: Formation of ovarian follicles during fetal development in sheep. Biol. Reprod. 2002, 66, 1134-1150.

47. Su Y. Q., Wu X., O’Brien M. J., Pendola F. L., Denegre J. N., Matzuk M. M. Eppig J. J.: Synergistic roles of BMP15 and GDF9 in the development and function of the oocyte-cumulus cell complex in mice: genetic evidence for an oocyte-granulosa cell regulatory loop. Dev. Biol. 2004, 276, 64-73.

48. Toda K., Takeda K., Okada T., Akira S., Saibara T., Kaname T., Yamamura K., Onishi S., Shizuta Y.: Targeted disruption of the aromatase P450 gene (Cyp19) in mice and their ovarian and uterine responses to 17beta-oestradiol. J. Endocrinol. 2001, 170, 99-111.

49. Varras M., Griva T., Kalles V., Akrivis C., Paparisteidis N.: Markers of stem cells in human ovarian granulosa cells: is there a clinical significance in ART? J. Ovarian Res. 2012, 5, 36.

50. Wandji S. A., Wood T. L., Crawford J., Levison S. W., Hammond J. M. Expression of mouse ovarian insulin growth factor system components during follicular development and atresia. Endocrinology 1998, 139, 5205-5214.

51. Yan C., Wang P., DeMayo J., DeMayo F. J., Elvin J. A., Carino C., Prasad S. V., Skinner S. S., Dunbar B. S., Dube J. L., Celeste A. J., Matzuk M. M.: Synergistic roles of bone morphogenetic protein 15 and growth differentiation factor 9 in ovarian function. Mol. Endocrinol. 2001, 15, 854-866.

52. Yuan W. Lucy M. C. Smith M. F.: Messenger ribonucleic acid for insulinlike growth factors-I and -II, insulin-like growth factor-binding protein-2, gonadotropin receptors, and steroidogenic enzymes in porcine follicles. Biol. Reprod. 1996, 55, 1045-1054.

53. Zuccotti M., Merico V., Belli M., Mulas F., Sacchi L., Zupan B., Redi C. A., Prigione A., Adjaye J., Bellazzi R., Garagna S.: OCT4 and the acquisition of oocyte developmental competence during folliculogenesis. Int. J. Dev. Biol. $2012,56,853-858$

Corresponding author: Bartosz Kempisty PhD, Department of Histology and Embryology, Department of Anatomy, Poznań University of Medica Sciences, 6 Swięcickiego St., 60-781 Poznań, Poland; e-mail: bkempisty@ ump.edu.pl 